\title{
Hairy Cell Leukemia and Bladder Cancer in a Patient: Relation with Dye Exposure and Review of the Literaure
}

\author{
Semra Paydas \\ Department of Oncology, Faculty of Medicine, Cukurova University, Adana 01330, Turkey \\ Correspondence should be addressed to Semra Paydas, sepay@cu.edu.tr \\ Received 11 October 2008; Accepted 30 January 2009 \\ Recommended by Estella M. Matutes
}

Chemical exposure is important in the etiology of some cancers. Dye or solvent exposures are important both in bladder cancer (BC) and hairy cell leukemia (HCL). Here a case with BC and HCL has been presented and literature has been reviewed.

Copyright (c) 2009 Semra Paydas. This is an open access article distributed under the Creative Commons Attribution License, which permits unrestricted use, distribution, and reproduction in any medium, provided the original work is properly cited.

\section{Case Report}

A 53-year-old man referred to our unit due to severe pancytopenia and splenomegaly. He had the history of pain during urination and hematuria for the last 2 years. He admitted to a urologist and bladder malignancy had been thought with abdominopelvic ultrasonographic examination. This US showed bladder wall thickness at the right-lower portion and massive splenomegaly with space occupying lesions in it, and it had been reported as BC and massive splenomegaly, probably spleen metastasis due to BC. PET/CT had been done and it showed thickening in bladder wall and splenomegaly with homogenous, low FDG uptake.

TUR had been performed due to $\mathrm{BC}$ by his urologist. After surgery, Mitomycin C instillation was given weekly for 4 weeks and one injection in every six months for four times is then given. After these he admitted to our unit with pancytopenia and splenomegaly.

His personal history was interesting for chemical exposure: he was interested with music and he was guitar player for years. He had the history of sellulosic dye exposure due to his professional job. He had the history of smoking and alcohol ingestion daily (whisky and Turkish raki) for 25 years.

Physical examination showed pallor and splenomegaly $8 \mathrm{~cm}$ below the left costal margin.

Abnormal laboratory tests are $\mathrm{Hb}: 7 \mathrm{~g} / \mathrm{dL}$, Hct: $21 \%$, WBC: $9.2 \times 10^{9} /$ lt with $5.7 \%$ neutrophil and $70 \%$ lymphoid cells, platelet: $64 \times 10^{9} / \mathrm{lt}$, ESR: $36 \mathrm{~mm} / \mathrm{h}$, ALP: $525 \mathrm{IU} / \mathrm{L}$,
GGT: 267 IU/L. Peripheral blood smear showed abnormal lymphoid cells with cytoplasmic projections and these cells were TRAP $(+)$ compatible with HCL.

Bone marrow biopsy showed grade III fibrosis and lymphoid infiltration and these cells were CD20 (+), TRAP $(+)$.

Management. Cladribine $0.1 \mathrm{mg} / \mathrm{Kg}$ daily for 7 days was given on December 2007. At the last visit on May 2008, his physical examination and complete blood count were within normal limits (Hb: $13.2 \mathrm{~g} / \mathrm{dL}$, Hct: $39.4 \%$, WBC: $4.3 \times 10^{9} / \mathrm{lt}$, neutrophil count: $2.65 \times 10^{9} / \mathrm{lt}$, platelet: $177 \times 10^{9} / \mathrm{lt}$.

\section{Discussion}

Urothelial cancer and dye exposure is an old history. The association between chemical exposure and $\mathrm{BC}$ is proposed classically but epidemiologic data is variable. When we enter the pubmed with "Bladder cancer and chemical" key words, it shows 795 papers. It has been reported in many papers that every type of exposure to chemicals (from occupational exposure to personal hair dyes or drinking water) may contribute to the occurrence of BC [1-5].

On the other hand, exposure to petroleum products and HCL is another aspect of the chemical exposure and cancer. First report about the chronic benzene exposure and HCL has been presented by Turkish Hematologist Aksoy [6]. After this observation, additional papers have been published about HCL and chemical exposures. However, due 
to the relative rarity of HCL the data about the association between chemical exposure and HCL, is limited. Male predominance in HCL (4/1) has been noticed by several groups, and this suggested the probability of occupational exposure to ionizing radiation, benzene, and other solvents $[7,8]$. In a case-control study covering 291 cases (229 men, 62 women) and 541 controls, there was a positive association between exposures to organic solvents or selfdeclared exposures to solvents and HCL [9]. In 2 casecontrol studies only male cases have been included. In the first study covering 111 male cases and 400 controls, there has been found elevated levels of antibodies to the EBV early antigen in HCL cases compared to controls. ORs were found to be elevated in cases with early antigen IgA and to have a history of exposure to environmental solvents, certain pesticides, impregnating agents, animals and exhausts [10]. In the second study, 121 male HCL cases and 484 controls have been included. Elevated OR was found for exposure to farm animals in general (OR: 2.0, CI: 1.2-2.3), exposure to herbicides (OR: 2.9, CI: 1.4-5.9), insecticides (OR: 2, CI: 1.1-3.5), fungicides (OR: 3.8, CI: 1.4-9.9), impregnating agents (OR: 2.4, CI: 1.3-4.6), organic solvents (OR: 1.5, CI: 0.99-2.3), and exhausted fumes (OR: 2.1, CI: 1.3-3.3) showed increased risk. In this study multivariate analysis showed elevated ORs for all these exposures with the exception of insecticides [11]. There are some smaller casecontrol studies evaluating HCL and chemical exposure. A study covering 45 cases and their neighborhoods evaluated exposure to organic chemicals in the workplace and there was significantly greater exposure in cases than controls (RR: 3.10). Employment in the woodworking or farming was of borderline significance. In this cohort there was a significant risk in farm birthplace (RR: 4.20), migraine (RR: 4.80), infectious mononucleosis (RR: 9), routine use of aspirin (RR: 3.41), and tranquilizers (RR: 4.5) [12]. In another casecontrol study covering 50 cases and 95 controls, there has been found an important risk between HCL and exposure to organic solvents, petrochemicals, and related products [13]. When evaluated generally, cigarette smoking was associated with reduced or no risk of HCL and this was an interesting point of these studies $[8,11,12]$.

In our case there was the history of dye exposure and double cancer that the etio-pathogenetic role of dye has been shown in both. This case is interesting due to 2 reasons:

(1) coexistence of HCL and BC in a case with the history of exposure to dye is interesting,

(2) epidemiologic data about the dye exposure and HCL is relevant, but we need additional epidemiological studies and/or meta-analysis about chemical exposures and HCL.

\section{References}

[1] M. A. Kelsh, D. D. Alexander, R. M. Kalmes, and P. A. Buffler, "Personal use of hair dyes and risk of bladder cancer: a metaanalysis of epidemiologic data," Cancer Causes and Control, vol. 19, no. 6, pp. 549-558, 2008.
[2] K. Golka and W. Weistenhöfer, "Fire fighters, combustion products, and urothelial cancer," Journal of Toxicology and Environmental Health Part B, vol. 11, no. 1, pp. 32-44, 2008.

[3] K. G. Brown, "Inorganic arsenic in drinking water and bladder cancer: a meta-analysis for dose-response assessment," International Journal of Environmental Research and Public Health, vol. 4, no. 2, pp. 193-194, 2007.

[4] A. D. Kaprin, G. A. Pan'shin, S. V. Garmash, A. A. Kostin, E. V. Khmelevskiı̌, and V. O. Yelagin, "An evaluation of damage caused by radiation and chemical drugs to urinary bladder mucosa in stage T1-T2N0V0 cancer," Voprosy Onkologii, vol. 53, no. 4, pp. 473-476, 2007.

[5] T. Weiss, T. Brüning, and H. M. Bolt, "Dephenylation of the rubber chemical $N$-phenyl-2-naphthylamine to carcinogenic 2-naphthylamine: a classical problem revisited," Critical Reviews in Toxicology, vol. 37, no. 7, pp. 553-566, 2007.

[6] M. Aksoy, "Chronic lymphoid leukaemia and hairy cell leukaemia due to chronic exposure to benzene: report of three cases," British Journal of Haematology, vol. 66, no. 2, pp. 209211, 1987.

[7] G. Flandrin and S. Collado, "Is male predominance (4/1) in hairy cell leukaemia related to occupational exposure to ionizing radiation, benzene and other solvents?" British Journal of Haematology, vol. 67, no. 1, pp. 119-120, 1987.

[8] G. Flandrin and B. Coiffier, "Perspectives for an epidemiological study of hairy cell leukemia," Comptes Rendus de l'Académie des Sciences. Série III, vol. 307, no. 3, pp. 105-107, 1988.

[9] J. Clavel, L. Mandereau, S. Cordier, et al., "Hairy cell leukaemia, occupation, and smoking," British Journal of Haematology, vol. 91, no. 1, pp. 154-161, 1995.

[10] M. Nordström, L. Hardell, A. Linde, L. Schloss, and A. Näsman, "Elevated antibody levels to Epstein-Barr virus antigens in patients with hairy cell leukemia compared to controls in relation to exposure to pesticides, organic solvents, animals, and exhausts," Oncology Research, vol. 11, no. 11-12, pp. 539-544, 1999.

[11] M. Nordström, L. Hardell, A. Magnuson, H. Hagberg, and A. Rask-Andersen, "Occupational exposures, animal exposure and smoking as risk factors for hairy cell leukaemia evaluated in a case-control study," British Journal of Cancer, vol. 77, no. 11, pp. 2048-2052, 1998.

[12] D. Oleske, H. M. Golomb, M. D. Farber, and P. S. Levy, "A case-control inquiry into the etiology of hairy cell leukemia," American Journal of Epidemiology, vol. 121, no. 5, pp. 675-683, 1985.

[13] A. Staines and R. A. Cartwright, "Hairy cell leukaemia: descriptive epidemiology and a case-control study," British Journal of Haematology, vol. 85, no. 4, pp. 714-717, 1993. 


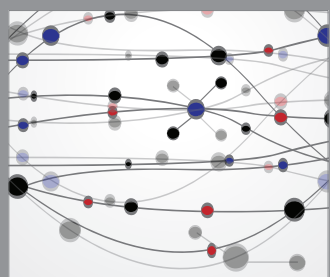

The Scientific World Journal
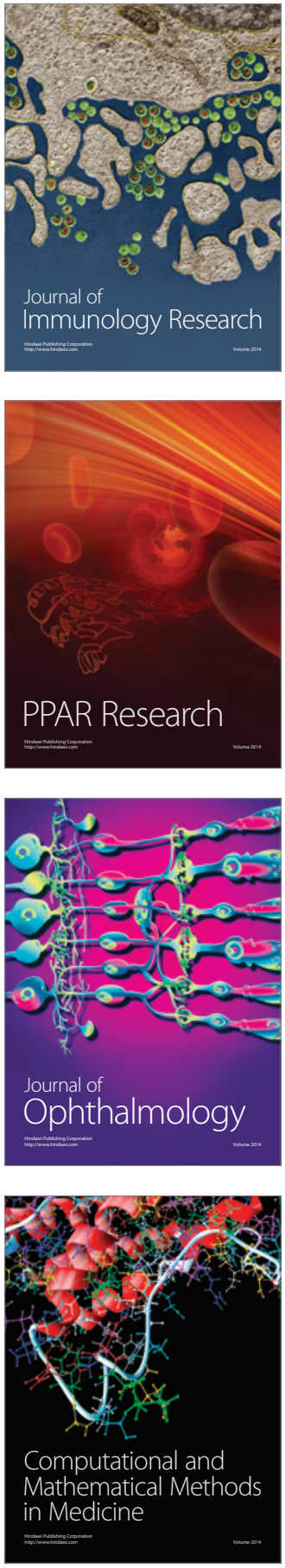

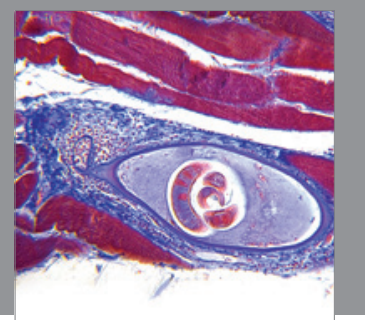

Gastroenterology

Research and Practice
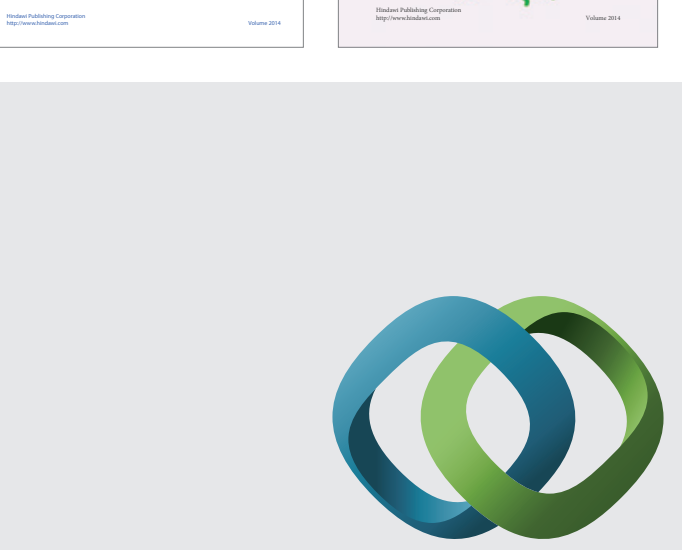

\section{Hindawi}

Submit your manuscripts at

http://www.hindawi.com
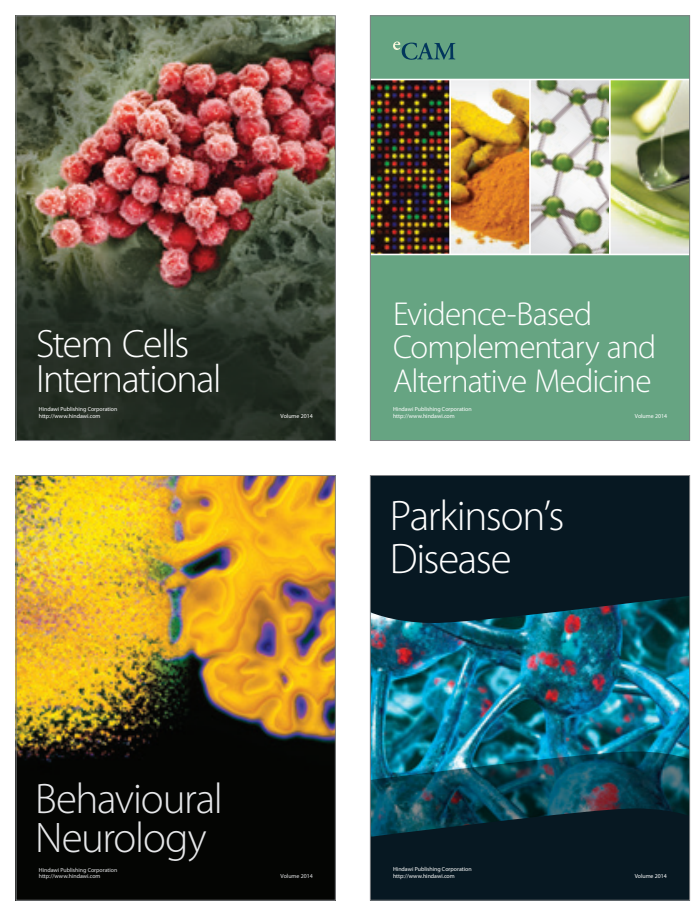

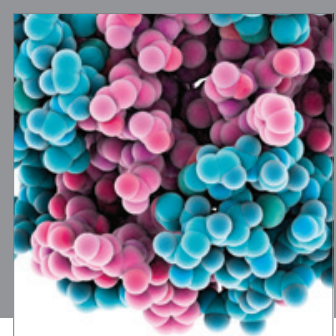

Journal of
Diabetes Research

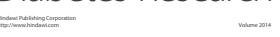

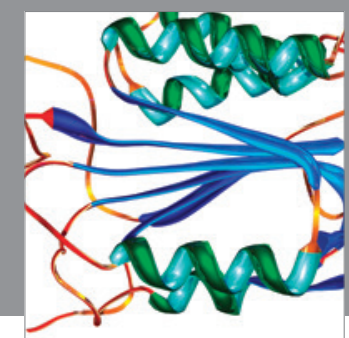

Disease Markers
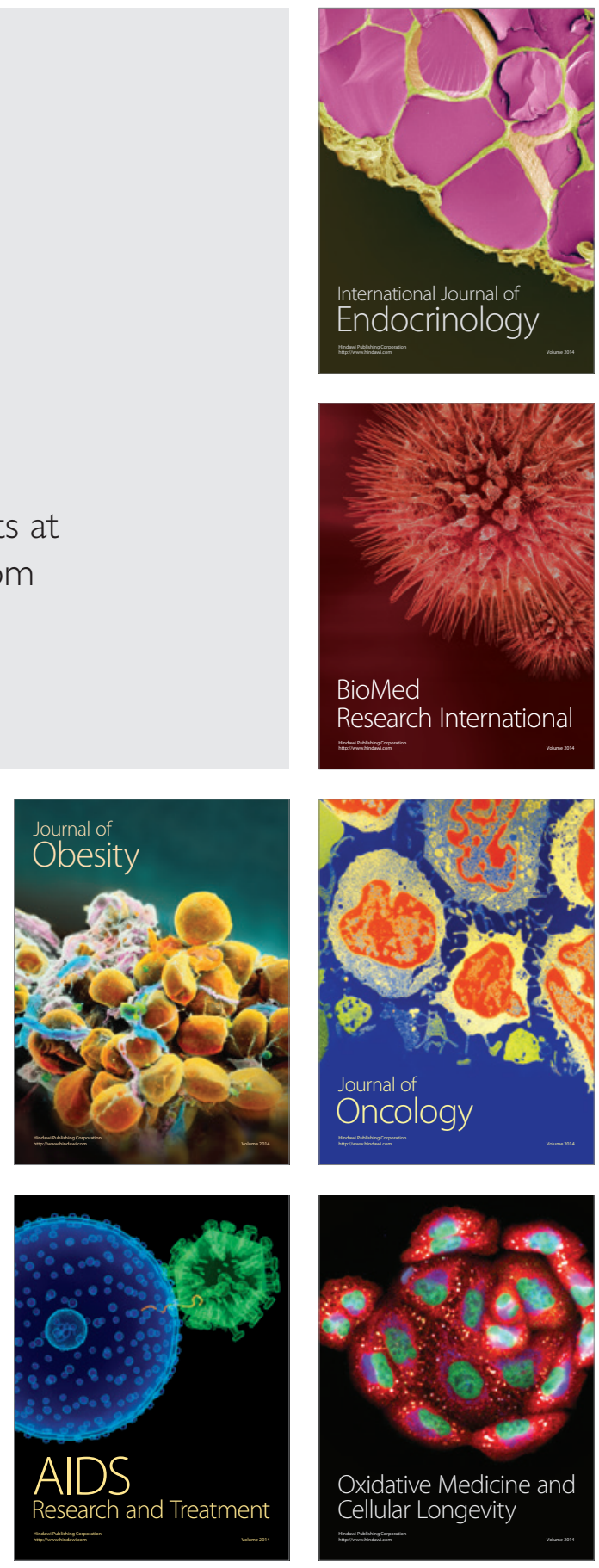